\title{
AC 2012-4460: JUNIOR CYBER DISCOVERY: CREATING A VERTICALLY INTEGRATED MIDDLE SCHOOL CYBER CAMP
}

\author{
Dr. Heath Tims, Louisiana Tech University \\ Prof. Galen E. Turner III, Louisiana Tech University \\ Mr. G.B. Cazes, Cyber Innovation Center
}

G.B. Cazes currently serves as the Cyber Innovation Center's (CIC) Vice President, responsible for its daily operations. In addition, Cazes has devoted countless hours to the development and implementation of a dynamic Academic Outreach and Workforce Development program. This program will assist the CIC in developing a knowledge-based workforce for the future. Cazes has spent his entire career in the information management and information technology sectors. His experience includes working in the international, commercial and government markets. Throughout Cazes' career, his responsibilities have included business development, marketing, public relations, finance, strategic planning, operations, and management. Cazes also serves as an advisor on multiple boards for various non-profits throughout the region. Previously, Cazes has served as the Assistant Director of the Information Technology Consulting Department. In this capacity, Cazes started the Mobile Development Group which focused on automating business processes through handheld devices. Cazes also served as the Director of Telecommunications Management Department and became a member of the Executive Team of Shreveport headquartered IT consulting and software development company.

Ms. JoAnn M. Marshall, Cyber Innovation Center 


\title{
Junior Cyber Discovery: Creating a Vertically Integrated Middle School Cyber Camp
}

\begin{abstract}
This paper describes an innovative partnership that was developed between high schools and their feeder middle schools in an effort to foster collaboration and mentoring among faculty while immersing rising $7^{\text {th }}$ grade students in a week-long, project-driven day camp to develop interest and skills in the fields of science, technology, engineering, and math (STEM). The middle school teachers received professional development and mentoring from their high school peers in addition to hands-on training with their students throughout the program. The students participated in activities that explore artificial intelligence and virtual reality which in turn cultivated their interest in the science and engineering aspects of cyberspace through interactive hands-on robotics and 3-D modeling. Socratic discussions concerning the social implications of the concepts presented were explored in depth through the use of movies that directly related to artificial intelligence and virtual reality. Examples from the camp will be presented along with lessons learned.
\end{abstract}

The United States faces an unprecedented challenge in foreign competition in math, science, and engineering. Locally, we face the challenge of preparing a workforce versed in cyber issues as well as math, science, and engineering to fulfill the needs of the region. The problem over the last decade is that there has been a 50\% decline in the students' interest in engineering and a 14\% decrease in engineering degrees with only $2.1 \%$ of high school graduates likely to earn an engineering degree. This project cultivates an interest in cyber, computer programming, math, science, and engineering by exposing middle school teachers and their students to the new technology.

The Cyber Discovery model was developed through a collaboration of mathematics, science, engineering, and liberal arts faculty from Louisiana Tech University and by staff from Cyber Innovation Center. The total immersive experience was aimed at high school teachers and their student teams. The culminating week-long residential camp exposed student participants to multiple topics of cyberspace including: history of cyberspace, ethical and social issues, applications, and the need for and use of security in cyberspace.

Similar to Cyber Discovery, where the focus is on building relationships between university and high school faculty; Junior Cyber Discovery is a collaboration between teams of STEM and humanities teachers at the high school and middle school levels. Junior Cyber Discovery model engages middle school students. 


\section{Introduction}

In Preparing the Next Generation of STEM Innovators: Identifying and Developing Our Nation's Human Capital, the National Science Board makes it clear that interventions are needed to recruit and develop students in the STEM fields so that our nation can maintain its position as a global leader in science and technology [1]. To demonstrate this point, the report goes on to cite statistics that show a decline in top United States students entering STEM fields and an increase in reliance on foreign-born talent [1]. This report is one of many that presents a call to action to universities and K-12 systems to evaluate and incorporate innovative changes into formal and informal teaching methods.

While hundreds of universities, public and private schools, and non-profit organizations have answered this call with their individual programs, a more unified effort that breeds systemic change may be the answer. The Cyber Discovery model employs dynamic curricula that was developed by university instructors and that impacts high school teachers and students. The core of the model is a professional development element that creates mentoring relationships, increases teacher confidence, and fosters systemic change through empowerment that, in turn, influences increased awareness and interest in STEM by students. Collaboration among university, high school, and middle school teachers has now produced a Junior Cyber Discovery effort that has the same potential for success as the Cyber Discovery model and potential for replication at the elementary level.

\section{Foundation of the Project}

Junior Cyber Discovery is based on the Cyber Discovery model first established by Louisiana Tech University and the Cyber Innovation Center in Summer 2008. Cyber Discovery Camp is an intensive week-long residential summer program that immerses high school teachers and students in the world of cyber. While STEM concepts such as engineering, computer science, and mathematics (cryptography) are emphasized, they are weaved together with carefully selected content from English, history, ethics, and political science. By integrating the humanities with STEM concepts, students are provided a context for the content being taught. The camp provides the opportunity for teachers and students to 1) better understand the history of cyberspace, cryptography, and cyber security; 2) experience cyber applications and programs; 3) discuss social and ethical implications of cyber; 4) explore possible cyber career fields; and 5) gain an appreciation for the need to secure cyberspace. The dynamic interactive camp curriculum consists of hands-on labs, a cryptographic treasure hunt, writing assignments, evening film sessions, and a Final Cyber Challenge. The Parallax Boe-Bot ${ }^{\mathrm{TM}}$ is used as the core teaching platform throughout.

In the months preceding the camp, high school teachers, one science/mathematics teacher and one humanities teacher from each school, attend two professional development workshops. Faculty from Louisiana Tech University's College of Engineering and Science and the College 
of Liberal Arts conduct the workshops in a team effort. The purpose of the workshops is for the university faculty to introduce the high school teachers to fundamental topics of the curricula. This introduction is key as it has been found that teachers "being educated in traditional education institutions receive little or no education on engineering concepts" [2]. Once high school teachers embrace the STEM concepts and feel confident in articulating them to the students, the university faculty members demonstrate how the camp projects will be used to reinforce the STEM concepts for the students. The Cyber Discovery model goes beyond projectbased curricula that simply instructs teachers on how to deliver a project. Rather, the model utilizes project-driven curricula that empowers teachers with the fundamentals to teach STEM and encourages the use of projects to drive the fundamentals home. These lessons and the other skills developed through the program can later be applied in the classroom. High School teachers are encouraged to provide feedback throughout this process, as they know their students' capabilities and interests best.

Additionally, workshops serve as an opportunity for the university faculty and the high school teachers to collaborate and to develop a mentoring relationship. The mutual respect and spirit of collaboration at the root of the mentoring relationship serve both the university faculty and the high school teachers well as they engage the student teams in the camp curricula and challenges. These mentoring relationships continue after the camp ends and are mutually beneficial. High school teachers seek out their university mentors on incorporating innovative lessons into the existing high school curricula and university faculty develop a better understanding of the level preparedness of the high school students who enroll in the summer programs and who are recruited to the university.

Once at camp, the high school teachers receive hands-on training as they guide their students through small group and full group activities from 8:00 a.m. to 11:00 p.m. each weekday. These activities prepare the teams for the Final Cyber Challenge held on Saturday morning. A typical day at the camp is divided into various topics, and incorporates various means of group interaction. Sessions may involve the entire camp, school groups, or mixed small groups where individuals are randomly assigned to help create diverse new interactions. Below is a sample of a typical Cyber Discovery camp day.

$\begin{array}{ll}\text { 8:00-9:00 } & \text { Breakfast } \\ \text { 9:00-9:30 } & \text { Movie Discussions (Mixed Small Groups) } \\ \text { 9:30-11:00 } & \text { Hands-On Lab (Full Group) } \\ & \text { Topic: Engineering Activity }\end{array}$

11:00-11:15 Break 
11:15-12:00 Cyber Policy and Ethics (Full Group)

Example Themes:

Security vs. Civil Liberties

Behavior Modifications

State-Sponsored Threats

Non-State Threats

$\begin{array}{ll}\text { 12:00-1:00 } & \text { Lunch } \\ \text { 1:00-1:45 } & \text { Cyber Policy \& Ethics Case Study (School Groups) } \\ \text { 1:45-2:00 } & \text { Break } \\ \text { 2:00-3:00 } & \text { Hands-On Lab (Full Group) } \\ & \quad \text { Example Topics: } \\ & \quad \text { Cryptography } \\ & \text { Manipulation } \\ & \text { Exploitation }\end{array}$

3:30-5:30 Team Time (School Groups)

5:30-6:30 Dinner

7:00-9:00 Move Time (Full Group)

Themes related to Cyberspace

9:30-11:00 Team Time in rooms (School Groups)

Cyber Discovery began in Summer 2008 with a total of 10 teachers and 30 students from 5 schools. In 2009, the camp expanded to 16 teachers and 48 students from 8 schools. The camp grew to 20 teachers and 60 students and 20 teachers and 55 students from 10 schools in 2010 and 2011, respectively. The strong reputation of the camp not only attracts more applications from schools than spots available, but some high schools have up to 100 students vying for the 6 spots allotted to each school.

Four years have passed since the pilot of Cyber Discovery in 2008 and the impact of the camp on the students is becoming more and more evident. One assistant principal stated, "Cyber Discovery changed our school; it became 'cool' to be an academically minded student. The Cyber Discovery students became the leaders of their 10th grade class and now the school." The students who attended the pilot Cyber Discovery Camp in 2008 have now graduated from their respective high schools and enrolled in universities. Three students from the pilot program reported changes in their college plans as a direct result of their Cyber Discovery experience. One male student who was originally focused on liberal arts decided to supplement his education by pursuing a dual degree in Computer Information Sciences and Business, while one female student changed her major from pre-med to biomedical engineering. Another male student 
decided to major in mechanical engineering and then pursue a masters in electrical engineering after exploring engineering concepts at Cyber Discovery Camp.

The impact on the teachers who have participated in the Cyber Discovery model over the last few years is equally as significant. Those teachers have become the leaders of their schools for developing new curricula in cyberspace. Several have integrated science into English courses, while others have developed STEM-specific courses that integrate with social studies or history [3]. Many of these teachers have sought out additional professional development opportunities through Louisiana Tech University and the Cyber Innovation Center, and have requested more innovative programs in which they can participate with their students.

\section{Project Description}

Junior Cyber Discovery is a demonstrated success of the Cyber Discovery model and resulted from the requests of principals and teachers for similar programs for their feeder middle schools. Three high school teachers who participated multiple times in the Cyber Discovery model recognized both the potential and need to modify the curricula for middle school teachers and their students. They approached Louisiana Tech University, Cyber Innovation Center, and their local school district with the idea and were met with enthusiasm. Based on their level of experience with the Cyber Discovery model, the three teachers, two science teachers and one humanities teacher, were deemed "master teachers" and committed to developing the integrated Junior Cyber Discovery model.

Junior Cyber Discovery Camp, a component of the overall model, is a five-day, non-residential program that allowed middle school teachers and their students to experience STEM through hands-on activities and instruction provided by Cyber Discovery "master teachers." The purpose of the program was to introduce teachers and students to STEM concepts while demonstrating how STEM impacts their daily lives and how they can become better cyber citizens. Rather than using a textbook or lectures for instruction, the instruction was centered on a robotics platform. Students worked in teams of six to not only build and program robots, but also to design key parts on a computer aided design (CAD) stations. To help students understand the role of technology in their daily lives, they participated in interactive discussions, performed skits, wrote creative essays, and gave formal presentations on technology-related topics.

Junior Cyber Discovery was offered as a pilot program during Summer 2011. A total of six teachers and eighteen students, all rising seventh graders, from two public middle schools attended the pilot program. Each team was led by two teachers, one science teacher and one humanities teacher.

Prior to the camp, the three high school teachers facilitated a collaborative professional development workshop with their middle school peers in order to provide an orientation to the curricula and to ensure that that the activities were both challenging and appropriate for the grade 
level. Like the Cyber Discovery model, the Junior Cyber Discovery professional development workshop focused first on the STEM concepts and then demonstrated how the projects reinforce the concepts for the students. Furthermore, the high school teachers mentored middle school teachers on how to integrate innovative STEM applications in their classrooms. Similar projects have shown that this integration can improve interactions between teachers and students throughout the school year [3]. Once again teachers received hands-on training so that they could effectively deliver a project-driven curriculum that not only engaged their students but also provided a context for the STEM content. This approach has demonstrated an ability to answer the "why" questions young students so often pose.

\section{Implementation}

Junior Cyber Discovery provided middle school teachers the opportunity to experience hands-on training with their students and gave students a better understanding of STEM that will prepare them for high school level courses. Together, the high school teachers and middle school teachers guided each team of students through the daily schedule of activities on Monday through Thursday that began at 8:30 a.m. and ended at 3:30 p.m. Below is an example of a typical day:

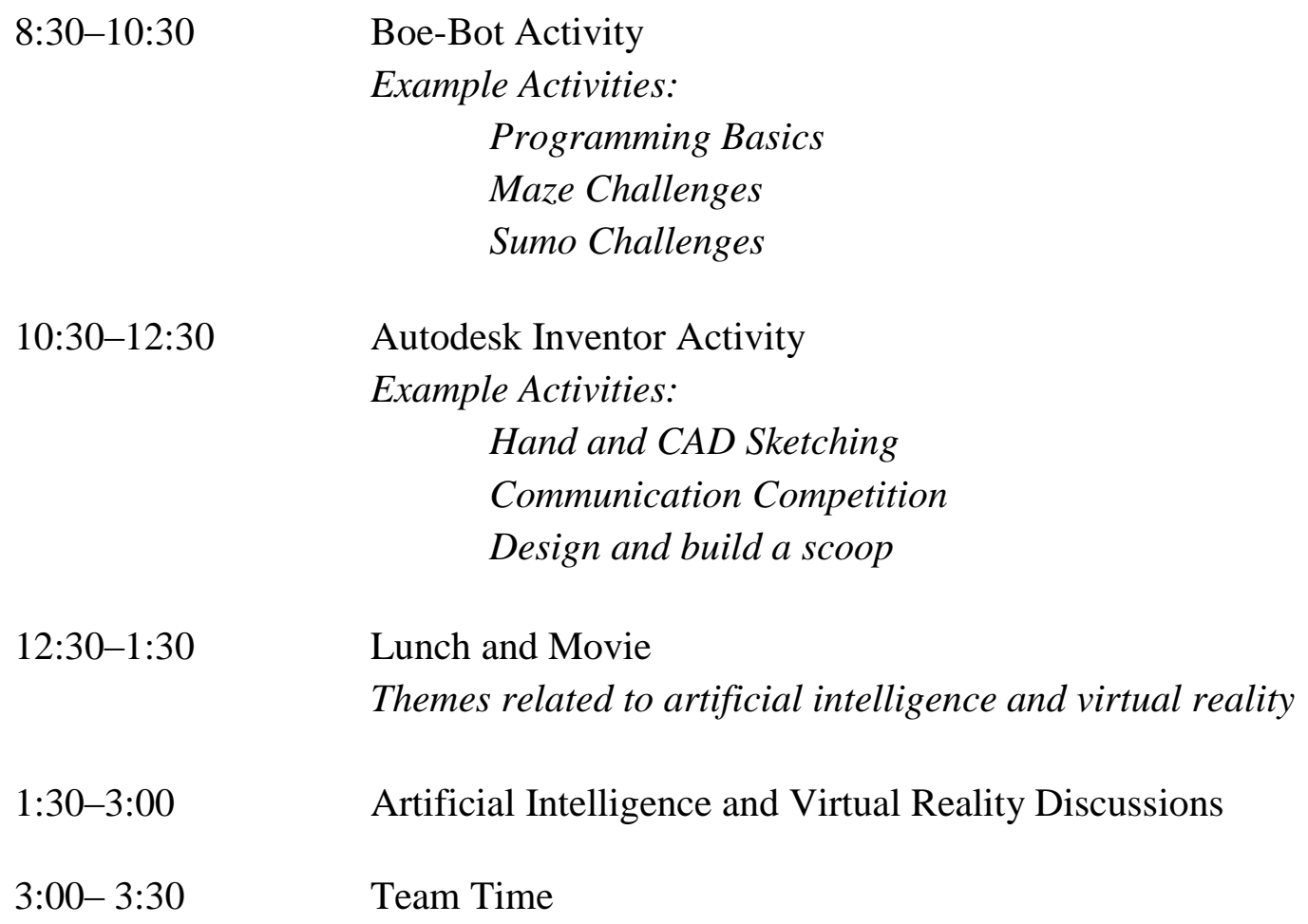




\section{Sample Activities}

Hands-On Lab, Boe-Bot: The use of a robotics platform served as a way to introduce basic concepts of programming, logic, and controls. In addition, the use of a hands-on robotic activity provided a mechanism for teaching problem solving.

Hands-On Lab, Autodesk Inventor: The use of Autodesk Inventor served as way to introduce virtual reality concepts. The students assembled a virtual model of the robot and then used the design process to create the scoop to go on the front of the robot for the final challenge. This tool also helped the students develop problem solving skills.

Movie and Discussions: At lunch each day, students and teachers were shown a film pertaining to cyber, artificial intelligence, and virtual reality. Films screened included: AI, I,Robot, Star Trek: Generations, and Spy Kids 3-D. Following each screening, students and teachers participated in a discussion and/or group activities related to the themes of the films.

Creative Arts: Each team was asked to develop a storyline that explained why they were building the robot and what the robot would do. These stories were brought to life through creative essays and skits.

Cyber Challenge: The camp culminated with a Cyber Challenge, which consisted of team presentations and the final sumo robot competition, on Friday. Team presentations provided an opportunity for students to weave together the week's worth of activities and to share what they have learned. The sumo robot competition demonstrated the team's success in programming and designing their robots. Each team's robot was pitted against another in an autonomous battle during which the robots located, attacked, and pushed their opponent out of the sumo ring.

\section{Professional Development Ladder}

The uniqueness of Junior Cyber Discovery can be found in the strategies used in its development. The majority of American K-12 engineering programs target high school students and teachers, as compared to younger students with 77 percent focused on high school students and 46 percent on high school teachers [4]. This program targets middle school students who have had little exposure to real engineering problems. Furthermore, Junior Cyber Discovery Camp emphasis is on the professional development for the teachers, both high school teachers and middle school teachers.

By employing the train-the-trainer method of empowering high school teachers to mentor middle school teachers, both parties benefit. The high school teachers have the opportunity to hone their STEM and humanities skills by reexamining the content from the Cyber Discovery model and developing strategies to deliver that content in a context that is relevant and appealing to middle school teachers and students. They must ask and answer the following questions: How do we 
integrate STEM and liberal arts? How do we convey the importance of STEM? How do these concepts apply to the real world? The middle school teachers benefit from the skills developed through the professional development and camp experiences and, at the same time, enter into a mentoring relationship with the high school teachers that can have long-term benefits.

One high school teacher stated, "Building a collaborative relationship with our middle school faculty counterparts is invaluable. We're learning about the challenges they face in working with middle school students and they are getting a better feel for the skills we are looking for in preparing students for the rigors of a high school curriculum. We are also collaborating on ways to implement project-based learning in our middle and high school classrooms."

The potential for this professional development model is two-fold. First, the faculty from Louisiana Tech University can create more "master teachers" through continuous training of high school teachers who participate in the Cyber Discovery model. While preserving the integrity of the Cyber Discovery model, those "master teachers" can then develop Junior Cyber Discovery program with their respective feeder middle schools. Second, with the proper training and guidance, the middle school teachers who participate in Junior Cyber Discovery can collaborate with elementary school teachers to develop a K-5 Cyber Discovery programs. This professional development model not only increases the number of teachers who will benefit from the training, but it also grows exponentially the number of students who will benefit as a result. Thus, a connection is established from the elementary to university level and systemic change is possible.

\section{Results/Observations}

The pilot of the Junior Cyber Discovery Camp included 6 teachers and 18 students, all rising seventh graders ranging in age from 12-13. There was an even distribution of male and female students with 9 males and 9 females, and all 6 teachers were female. The collaborators of the camp were pleased by the high number of female teachers and students who elected to participate in the program. The disparities of females in engineering are well documented [2]. Junior Cyber Discovery has learning methods like group, hands-on activities and real life applications of how STEM impacts people and the community every day that encourage female students [2] and may inspire them to seek out additional STEM opportunities. Early academic outreach programs like this may provide a positive introduction to engineering for female students that can help combat the current disparities in the field.

The following are questions from the Junior Cyber Discovery survey disseminated to the participating teachers several weeks after the camp when they were more capable of determining the camp's effects on both their students and their classroom. Teachers were asked to rate their response to several statements on a scale of 1-5 with 5 being the highest. All responses were in the $4-5$ range. 


\section{Questions:}

- I felt confident about coaching my students through the camp challenges

- The camp experience gave my students a better sense of the importance of STEM.

- I am confident that I can integrate other subject material into my science or humanities classes.

- I have examined and revised my classroom practices to include information and practices from the camp.

In the general comments section, one teacher qualified her rating of the camp by writing, "This was a valuable learning experience for students that prior to the camp had very little knowledge about STEM."

\section{Conclusion}

Junior Cyber Discovery has been offered only once to a small pilot group so it is difficult to make any definitive predictions for the future. The program was well-received by high school teachers, middle school teachers, and students alike. The feedback from the teachers, in particular, indicates changes in the classroom and collaboration between middle and high school. These results will have an overall positive impact. The feedback from the high school and middle school teachers will be considered before the program is offered next summer. The possibility of offering this program at the elementary level will also be considered.

The success of Cyber Discovery can offer insight into the success of the Junior Cyber Discovery. Cyber Discovery has grown since its inception in 2008 and is now being rolled-out as a national model through partner universities. Junior Cyber Discovery has the potential to follow the same pathway as partnerships are developed regionally and nationally.

\section{Acknowledgments}

We would like to acknowledge Benton and Parkway High Schools for providing the support and resources necessary to execute the Junior Cyber Discovery model. We would also like to acknowledge the master teachers who facilitated the pilot camp: Marvin Nelson from Benton High School and Dale Bozeman and Jeff Holcomb from Parkway High School. 


\section{References}

[1] National Science Board. Preparing the Next Generation of STEM Innovators: Identifying and Developing Our Nation's Human Capital. 2010.

[2] Sontgerath, Suzanne, S. Blaisdell, P. Wong, A. Swan, K. Ziemer. "Growing a STEM Team: Review of an Innovative Program for Middle School Students," Proceedings of the 2005 WEPAN/NAMEPA Joint Conference (2005).

[3] Tims, H., Turner, G., Duncan, C., and Etheridge, B. "Cyber Discovery Camp - Integrated Approach to Cyber Studies," Proceedings of the 2009 ASEE//IEEE Frontiers in Education Conference (2009).

[4] Chubin, Daryl, K. Donaldson, B. Olds, and L. Fleming. "Educating Generation Net - Can U.S. Engineering Wood and Win the Competition for Talent?," Journal of Engineering Education, Vol 97, No 3, 2008, pp 245-257. 